\title{
A comparison of iron absorption from single meals and daily diets using radioFe $\left.{ }^{55} \mathrm{Fe},{ }^{59} \mathrm{Fe}\right)$
}

\author{
BY PER TIDEHAG ${ }^{3,4}$, GÖRAN HALLMANS ${ }^{3,6}$, KENNETH WING $^{5}$, \\ ROLF SJÖSTRÖM', GÖRAN ÅGREN ${ }^{2}$, EVA LUNDIN ${ }^{3,6}$ \\ AND JIE-XIAN ZHANG ${ }^{3,6}$ \\ The ${ }^{1}$ Biophysics and ${ }^{2}$ Radiophysics Laboratories and the Departments of ${ }^{3}$ Nutritional Research, \\ ${ }^{4}$ Prosthetic Dentistry, ${ }^{5}$ Oral Radiology and ${ }^{6}$ Pathology, Umeå University, Umeå, Sweden
}

(Received 13 December 1994 - Revised 26 April 1995 - Accepted 10 May 1995)

\begin{abstract}
The purpose of the present study was to compare two measures of $\mathrm{Fe}$ absorption, one from single meals and the other from daily diets. Ten ileostomy subjects were given the same low-fibre composite diet for all three meals each day for five consecutive days. After 3 weeks the experiment was repeated with a highfibre diet. The morning meal constituted one-seventh of the total daily diet intake, the mid-day meal twosevenths and the evening meal four-sevenths of the total daily diet intake. On days 4 and 5 of each diet period the morning meal was labelled with ${ }^{55} \mathrm{Fe}$ and all three meals were labelled with ${ }^{59} \mathrm{Fe}$. The activities retained in the subjects $19 \mathrm{~d}$ later showed the Fe absorption from the low-fibre diet measured from the morning meals to be almost $80 \%$ greater than the average Fe absorption measured from all meals during the same $2 \mathrm{~d}$. With the high-fibre diet the absorption from the morning meals was less than $\mathbf{5 0} \%$ greater than the average for all meals but the difference was not significant. We suggest that all meals of the day should be labelled with radioFe in order to avoid inflating the measures of Fe absorption.
\end{abstract}

Iron: Non-haem-iron: Ileostomy

Fe deficiency has for a long time been one of the most prevalent nutritional deficiencies in the world (Expert Scientific Working Group, 1985). Fe absorption from food is dependent on the Fe requirements of the individual and on the amount and bioavailability of dietary $\mathrm{Fe}$, which is affected by various dietary factors. It is important, therefore, to have accurate and reliable methods for measuring Fe absorption from both individual foodstuffs and whole meals. The method most often used for measuring Fe absorption is the retention of a radioisotope of $\mathrm{Fe} 2-3$ weeks after the ingestion of a radioisotope-labelled foodstuff, meal or diet. This method was first described by Hallberg \& Björn-Rasmussen (1972) who used two radioisotopes of $\mathrm{Fe}$. The method was developed primarily for measuring Fe absorption from whole diets, but later became used increasingly frequently in the study of the effects of specific inhibitors on Fe absorption from single meals. However, it has been suggested that single-meal studies overestimate the effects on $\mathrm{Fe}$ absorption of enhancers and inhibitors in the diet (Cook et al. 1991). Recently, a variation of the single-meal method has been used (Cook et al. 1991; Gleerup et al. 1995) in which one or all meals each day for a period of up to $14 \mathrm{~d}$ were labelled with radioFe. In these studies, where diet was varied from meal-to-meal and day-to-day, the effects of inhibitors on the absorption of radioFe were less pronounced than those observed in single-meal studies. Cook et al. (1991) concluded that a plausible explanation for the difference between single-meal and wholediet results was that 'the influence of dietary inhibitors and enhancers is diluted in a normal diet by meals that have no overall effect on non-haem-Fe absorption'. While it is possible also that the design of measurements of Fe absorption (single meal $v$. diet) affect the results 
and their interpretation, this cannot be decided on the basis of the results of studies in which both the circumstances and the diets were varied at the same time.

The aim of the present study was to compare Fe absorption from a morning meal (labelled with ${ }^{55} \mathrm{Fe}$ ) with $\mathrm{Fe}$ absorption from all three meals of the day (labelled with ${ }^{59} \mathrm{Fe}$ ) on two consecutive days using the same diets in all meals. The experiment was repeated with both a low-fibre (LFD) and a high-fibre (HFD) diet.

\section{SUBJECTS AND METHODS}

Subjects

Ten subjects, two females aged 34 and 51 years and eight males aged 43-65 years (mean age 54.4 years), volunteered to participate in the experiment. The subjects were given written and oral information about the aims of the study and its design. The project was approved by the Ethical Committee of the Umeå University Hospital.

The subjects had been proctocolectomized for ulcerative colitis 8-29 years before the study (mean 16.0 years). A small segment of the small intestine had been removed, mostly less than $50 \mathrm{~mm}$ (range $<50-150 \mathrm{~mm}$ ). No signs of inflammation or of renal, liver or thyroid disease were found in routine laboratory tests. Their body weight at the beginning of the study ranged from 64 to 113 (mean 82.2 ) $\mathrm{kg}$ and from 64 to 111 (mean 82.0) $\mathrm{kg}$ at the end of the 5 -week study. There were no differences in mean body weight among the different periods.

\section{Study design and diets}

This comparative study of two measures of $\mathrm{Fe}$ absorption was performed within the framework of a larger study on the effects of the distribution of food intake during the day on mineral and sterol metabolism. The subjects were studied on an out-patient basis. During the first of two experimental periods, with five successive days for each period, they were given an LFD and during the second they were given an HFD. In each meal a nutritionally sufficient amount of $\mathrm{Ca}$ was available $(<200 \mathrm{mg})$, which has been shown previously to inhibit $\mathrm{Fe}$ absorption measured with radioFe (Hallberg et al. 1991). The two study periods were separated by $16 \mathrm{~d}$. On days 1 and 2 of each $5 \mathrm{~d}$ experimental-diet period the subjects ate the experimental diet in their own homes according to explicit instructions. On days 3, 4 and 5 the subjects were admitted to the Research Ward and stayed overnight in a nearby hotel.

The LFD and HFD diets were the same except for the bread (Table 1). The bread in the LFD consisted of wheat-endosperm bread ( $70 \%$ extraction rate) and wheat crispbread (Wasabröd AB, Sweden), while the bread in the HFD was rye-bran bread and wholegrain rye crispbread (Wasabröd AB, Sweden). Each of the breads and crispbreads was baked in one batch.

The wheat-flour-based bread was supplemented with $2.37 \mathrm{mg} \mathrm{Fe} / 1$ soft bread as $\mathrm{Fe}_{2} \mathrm{SO}_{4} .7 \mathrm{H}_{2} \mathrm{O}$ in $100 \mathrm{ml} 0.01 \mathrm{M}-\mathrm{HCl}$ added to the dough providing a total of $5.5 \mathrm{mg} \mathrm{Fe}$ per portion of bread. (One portion in the $8500 \mathrm{~kJ}$ energy level (see below) corresponds to two and one-third pieces of wheat-endosperm bread.)

The subjects completed $3 \mathrm{~d}$ dietary recalls before the start of the experiment. Based on their energy intakes for the $3 \mathrm{~d}$ dietary recall and the recommendations of the Food and Agriculture Organization/World Health Organization/United Nations University (1985) they were given test diets with one of three energy levels: 8500,10600 and $12700 \mathrm{~kJ} / \mathrm{d}$ for both LFD and HFD. These energy levels corresponded to $1.0,1.25$ or 1.5 portions of the diet. The diet (Table 1) was consumed by each subject in three meals each day. The breakfast meal consisted of one-seventh of the total daily energy intake, lunch of twosevenths and dinner four-sevenths of the total energy intake during the day. The Swedish 
Table 1. The menus for the two test diets (one-seventh of a single daily portion; $g$ )

\begin{tabular}{|c|c|c|}
\hline Item & Diet period 1 & Diet period 2 \\
\hline Low-fat milk (0.5\% fat) & $100 \cdot 0$ & $100 \cdot 0$ \\
\hline Cheese $(28 \%$ fat $)$ & 5.0 & $5 \cdot 0$ \\
\hline Margarine (Delikatess; $15 \%$ linoleic acid) & $5 \cdot 0$ & $5 \cdot 0$ \\
\hline Smoked whitefish & $20 \cdot 0$ & $20 \cdot 0$ \\
\hline Mashed potatoes, dehydrated & 6.0 & $6 \cdot 0$ \\
\hline Tomato & 10.0 & $10-0$ \\
\hline Cucumber & 10.0 & 100 \\
\hline Cottage cheese $(4 \%$ fat $)$ & 10.0 & $10-0$ \\
\hline Coffee (freeze-dried) & $1 \cdot 0$ & $1 \cdot 0$ \\
\hline Sugar & $2 \cdot 0$ & $2 \cdot 0$ \\
\hline Milk chocolate & 3.6 & 3.6 \\
\hline \multicolumn{3}{|l|}{ Soft bread* } \\
\hline Wheat-flour-based & 20.4 (one-third of a piece) & - \\
\hline Whole-rye-grain-based & - & $25 \cdot 8$ (half a piece) \\
\hline \multicolumn{3}{|l|}{ Crispbread } \\
\hline Wheat-flour-based (Veteknäcke) & $13 \cdot 2$ (one piece) & _- \\
\hline Whole-rye-grain-based (Husman) & - & 13-0 (one piece) \\
\hline
\end{tabular}

* One piece of wheat-flour-based bread $(61 \cdot 1 \mathrm{~g})$ contained $(\mathrm{g})$ : wheat flour 37 , margarine 4 , sugar 4 , low-fat milk powder 4 , yeast 2 . One piece of rye-bran-based bread $(51.5 \mathrm{~g})$ contained $(\mathrm{g})$ : wheat flour 15 , rye bran 18 , margarine 3, sugar 3, low-fat milk powder 2, yeast 2 . The wheat-flour-based bread was supplemented with $2 \cdot 37 \mathrm{mg}$ $\mathrm{Fe} / 1$ soft bread added as $\mathrm{Fe}_{2} \mathrm{SO}_{4} .7 \mathrm{H}_{2} \mathrm{O}$ in $100 \mathrm{ml} 0.01 \mathrm{M}-\mathrm{HCl}$ to the dough, providing a total of $5.5 \mathrm{mg} \mathrm{Fe}$ per portion of bread.

Food Tables (Swedish National Food Administration, 1988) with a nutritional calculating program, Mats den flexible 3.0, were used to calculate the nutrient, fibre and energy contents of the test diets except for those in rye-bran bread and the wheat and rye crispbreads, for which values obtained by analysis were used (Table 2). The $\mathrm{Fe}$ and $\mathrm{Ca}$ contents of the diets were determined in our laboratory using an atomic absorption spectrophotometer (see p. 284).

During days 4 and 5 of each of the two experimental periods the subjects were given the breakfast meals labelled with ${ }^{55} \mathrm{Fe}$ and all three meals each day labelled with ${ }^{59} \mathrm{Fe}$. The radio-Fe solutions were pipetted onto one piece of bread for each labelled meal and allowed to dry before being served. Both radionuclides were obtained as the chloride in $0.1 \mathrm{M}-\mathrm{HCl}$ (Amersham International Plc, Amersham, Bucks.) and diluted with deionized water $(1: 10$, $\mathrm{v} / \mathrm{v}$ ). The amount of radioFe was related to the Fe content of the foods in order to obtain the same specific activity in each meal.

\section{Blood samples, haemoglobin and ferritin determinations}

Before and after each study period venous blood samples were withdrawn in the morning after an overnight fast to determine the blood haemoglobin and plasma ferritin concentrations. During day 3 of each of the periods blood samples were taken every hour during the day for metabolic measurements (not presented here). The same amount of blood was taken during the LDF and HDF periods. The haemoglobin concentration was determined spectrophotometrically at $540 \mathrm{~nm}$ using the cyanide method (International Committee for Standardization in Human Blood, 1965). One blood sample was allowed to stand for at least $15 \mathrm{~min}$. It was then centrifuged and a plasma sample was taken in a glass tube and frozen at $-70^{\circ}$. The ferritin concentrations were determined in the thawed plasma samples on the same occasion at the end of the experiment by the Clinical Laboratory of the University Hospital with an enzyme-linked immunosorbent assay using immunological 
Table 2. Composition of the test diets (amount per $d$ for subjects given one portion) ${ }^{* \dagger}$

\begin{tabular}{|c|c|c|}
\hline & Low-fibre diet & High-fibre diet \\
\hline Protein $(\mathrm{g})$ & $99 \cdot 4$ & $105 \cdot 5$ \\
\hline Fat $(g)$ & $76 \cdot 1$ & $71 \cdot 7$ \\
\hline Carbohydrate $(\mathrm{g}) \ddagger$ & 234.9 & $235 \cdot 6$ \\
\hline Dietary fibre $(\mathrm{g})$ & $12 \cdot 4$ & $41 \cdot 1$ \\
\hline Total energy (kJ)* & 8498 & 8450 \\
\hline From protein $(\%)$ & $19 \cdot 9$ & $21 \cdot 2$ \\
\hline From fat $(\%)$ & $33 \cdot 1$ & $31 \cdot 4$ \\
\hline From carbohydrate $(\%)$ & 47.0 & $47 \cdot 4$ \\
\hline $\mathrm{Fe}(\mathrm{mg})$ & 11.8 & $10 \cdot 2$ \\
\hline $\mathrm{Ca}(\mathrm{g})$ & $1 \cdot 47$ & 1.44 \\
\hline
\end{tabular}

* Other subjects were given either 1.25 or 1.50 times these amounts depending on which was closest to their ordinary energy intake.

$\dagger$ All values except $\mathrm{Fe}$ and $\mathrm{Ca}$ were calculated using the menus in Table 1 and data from Svenska Livsmedelstabellen. The values for $\mathrm{Fe}$ and $\mathrm{Ca}$ were determined on freeze-dried samples of the diets using flame atomic absorption spectrometry in our laboratory. The dietary fibre in wheat flour and rye bran was determined by an enzymic method as described by Asp et al. (1983).

+ Excluding dietary fibre.

reagents obtained from DAKO (Copenhagen, Denmark) and calibrated against World Health Organization Standards 80/578. During the experiment a total of $525 \mathrm{ml}$ blood was taken from each person for haemoglobin and plasma ferritin determinations and ${ }^{55} \mathrm{Fe}$ and ${ }^{59} \mathrm{Fe}$ activity measurements as well as other measurements pertinent to the main body of the study.

Determination of dietary iron, calcium, inositol phosphates and fibre contents

Six samples of $1 \mathrm{~g}$ each of the freeze-dried homogenized daily diets were taken in borosilicate tubes and ashed for $2 \mathrm{~d}$ at $550^{\circ}$. The ash was dissolved in $1 \mathrm{ml} 3 \mathrm{M}-\mathrm{HCl}$ and evaporated to dryness in an oven. The ash was dissolved again in $0.5 \mathrm{ml} 3 \mathrm{M}-\mathrm{HCl}$, left to stand overnight and diluted with $2 \mathrm{ml}$ water. The samples were further diluted with $0.6 \mathrm{M}$ $\mathrm{HCl}$ as necessary for determination of the $\mathrm{Fe}$ concentrations. For the determination of Ca concentrations, $\mathrm{La}_{2} \mathrm{O}_{3}$ in $0.6 \mathrm{M}-\mathrm{HCl}$ was added to a final concentration of $10 \mathrm{~g} \mathrm{La} / \mathrm{l}$. Both $\mathrm{Fe}$ and $\mathrm{Ca}$ concentrations were determined using a Varian Model AA-6DB atomic absorption spectrophotometer with an air-acetylene flame. Known amounts of $\mathrm{Fe}$ in $0.6 \mathrm{M}-\mathrm{HCl}$ and $\mathrm{Ca}$ in $0.6 \mathrm{M}-\mathrm{HCl}$ containing $10 \mathrm{~g} \mathrm{La} / 1$ were used as references. $\mathrm{All} \mathrm{HCl}$ used was Supra-pure ${ }^{\circledR}$ (Merck).

Dietary fibre was analysed using the enzymic method of Asp et al. (1983).

\section{Whole-body activity measurements}

\section{Measurement of iron absorption}

Before the first diet period, possible background activity at the gamma energies of ${ }^{59} \mathrm{Fe}$ in each subject was measured using the whole-body counter at the University Hospital in Umeå, Sweden. The counter is mounted in a chair geometry with an APGC detector with a relative efficiency of $36 \%$. At the time of the whole-body measurement, a blood sample was withdrawn to determine the activities of ${ }^{55} \mathrm{Fe}$ and ${ }^{59} \mathrm{Fe}$. At $19 \mathrm{~d}$ after the administration 
of a radioFe-labelled test diet the whole-body and blood activity measurements were repeated and the activity from the previous measurement was subtracted as background. ${ }^{55} \mathrm{Fe}:{ }^{59} \mathrm{Fe}$ in the blood sample was multiplied by the whole-body retention of ${ }^{59} \mathrm{Fe}$ to calculate the whole-body retention of ${ }^{55} \mathrm{Fe}$.

\section{Blood activity measurements}

Analyses of ${ }^{55} \mathrm{Fe}$ and ${ }^{59} \mathrm{Fe}$ in blood were made using the method of Eakins \& Brown (1966) as described by Bothwell et al. (1979) and modified as follows:

(1) In the original method blood samples are wet-ashed with $\mathrm{H}_{2} \mathrm{SO}_{4}, \mathrm{HNO}_{3}$ and $\mathrm{HClO}_{4}$, while in the present study blood samples were dry-ashed. Samples of $10-20 \mathrm{ml}$ blood containing no more than $10 \mathrm{mg} \mathrm{Fe}$, as determined from haemoglobin content, were placed in $50 \mathrm{ml}$ borosilicate-glass beakers. The blood was dried for $48 \mathrm{~h}$ starting at $80^{\circ}$ and increasing slowly to $120^{\circ}$. The temperature was then raised very slowly to and maintained at $550^{\circ}$ in order to ash the blood samples. The total ashing time was $48 \mathrm{~h}$. The samples were allowed to cool and the ash was dissolved in $5 \mathrm{ml}$ concentrated $\mathrm{HCl}$ and $1 \mathrm{ml}$ concentrated $\mathrm{H}_{2} \mathrm{SO}_{4}$. The solution was heated on a hot plate in a fume hood until white fumes were produced and then maintained at this temperature for another $10 \mathrm{~min}$. The samples were then allowed to cool, $10 \mathrm{ml}$ concentrated $\mathrm{HCl}$ was added and the solution was heated without boiling until approximately $5 \mathrm{ml}$ remained. The solution was then filtered through a sterile filter (Sterile Acrodisc $0.2 \mu \mathrm{m}$; Gelman Sciences, Ann Arbor, MI, USA) into a $18 \times 150 \mathrm{~mm}$ siliconized borosilicate glass tube using a $1 \mathrm{ml}$ disposable syringe. The beaker, syringe and filter were rinsed five times with $1 \mathrm{ml} 3 \mathrm{M}-\mathrm{HCl}$. The necessity for this filtration procedure is as yet untested.

(2) Step 2.20 (stirring of the precipitate). After mixing the precipitate with water in the tube, it was allowed to stand overnight. This step allowed colloidal particles to precipitate before centrifugation.

(3) Insta-Fluor ${ }^{\star}$ liquid scintillation cocktail (Packard Instrument Company, Downers Grove, IL, USA) was used instead of Aquasol ${ }^{\circledR}$. The activities of ${ }^{55} \mathrm{Fe}$ and ${ }^{59} \mathrm{Fe}$ in blood samples thus prepared were measured using a liquid-scintillation counter (LKB Wallac 1214 Turku, Finland).

\section{Method error and precision}

In order to ascertain the precision of the dry-ashing method for the determination of ${ }^{55} \mathrm{Fe}$ and ${ }^{59} \mathrm{Fe}$ activities in blood and the possible systematic error in the method, three $10 \mathrm{ml}$ blood samples were taken from each subject at the time of the measurement of the absorption of the reference doses 3 weeks after their administration. Duplicate samples were prepared on two separate occasions using the dry-ashing method developed in the present study, while the third sample was wet-ashed at the National Veterinary Institute, Uppsala, Sweden with $\mathrm{H}_{2} \mathrm{SO}_{4}, \mathrm{HNO}_{3}$ and $\mathrm{HClO}_{4}$ according to the original method (Frank, 1976). The ${ }^{55} \mathrm{Fe}$ and ${ }^{59} \mathrm{Fe}$ activities in all three samples were then measured on the same occasion according to step 3 in the method described previously. There was no statisticallysignificant systematic difference in the value obtained for the duplicate samples which were dry-ashed on two separate occasions for either radioisotope or for the ratio of their activities $(t 0.64-1.35, P>0.05)$. The precision of the measurement of ${ }^{55} \mathrm{Fe}$ was $2.3 \%$, for ${ }^{59} \mathrm{Fe}$ it was $1.6 \%$ and for ${ }^{55} \mathrm{Fe}:{ }^{59} \mathrm{Fe}$ it was $1.5 \%$. The values for the duplicate dry-ashed samples were then combined into a mean value and these means were tested against the values obtained with the wet-ashed samples for the same subject and radioisotope or ratio. The values for the ${ }^{55} \mathrm{Fe}$ and ${ }^{59} \mathrm{Fe}$ activities and their ratio obtained with the two methods were very closely and significantly correlated with each other $(r>0.98, P<0.001)$. The values obtained from the wet-ashed samples were on average slightly higher $\left({ }^{55} \mathrm{Fe} 1.0\right.$ (SE 
$0.91) \%$ and ${ }^{59} \mathrm{Fe} 2 \cdot 0(\operatorname{SE} 0 \cdot 80) \%$ ) than the corresponding values for the dry-ashed samples. While the mean difference between the values obtained for the ${ }^{59} \mathrm{Fe}$ activity with the two methods was significant $(t 2.91, P=0.017)$, the mean difference for the ${ }^{55} \mathrm{Fe}$ activity and ${ }^{55} \mathrm{Fe}:{ }^{59} \mathrm{Fe}$ were not $(t 1.38$ and 1.96 respectively, $P>0.05)$.

\section{Reference doses}

The day after the third whole-body measurement the subjects received reference doses of both ${ }^{59} \mathrm{Fe}$ and ${ }^{55} \mathrm{Fe}$ on two consecutive mornings after a $12 \mathrm{~h}$ overnight fast. $\mathrm{Fe}^{2+}(3 \mathrm{mg})$ labelled with both radioisotopes was administered as $\mathrm{FeSO}_{4}$ together with $30 \mathrm{mg}$ ascorbic acid in $10 \mathrm{ml} \mathrm{0-01} \mathrm{M}-\mathrm{HCl}$. The subjects drank the solutions directly from the vials and the vials were then rinsed three times with water which was also consumed. No food or drink was allowed for $3 \mathrm{~h}$ after the dose was given. At $19 \mathrm{~d}$ after the reference dose was given the whole-body and blood sample measurements were repeated. Each subject received a total of $273 \mathrm{kBq}{ }^{59} \mathrm{Fe}$ and $390 \mathrm{kBq}{ }^{55} \mathrm{Fe}$ in the test diets and $25 \mathrm{kBq}{ }^{59} \mathrm{Fe}$ and $39 \mathrm{kBq}^{55} \mathrm{Fe}$ in the reference doses.

\section{Statistical analysis}

Because the distribution of the plasma ferritin concentration was skewed, the data are presented as geometric means and their standard errors and the statistical tests on mean ferritin concentrations were performed using the logarithms of the ferritin values. The differences among time-points for ferritin and blood haemoglobin concentrations were tested using a one-way ANOVA for repeated measurements within subjects (Snedecor \& Cochran, 1980). If the one-way analysis was significant, differences between haemoglobin and plasma ferritin were tested using a paired $t$ test. Differences between measures of Fe absorption $\left({ }^{55} \mathrm{Fe}\right.$ and ${ }^{59} \mathrm{Fe}$ ) were also tested using a paired $t$ test. Pearson product-moment correlation coefficients were calculated for retention of ${ }^{55} \mathrm{Fe}$ and ${ }^{59} \mathrm{Fe}$. In each of the statistical tests we chose to reject the null hypothesis at the $5 \%$ level $(P \leqslant 0.05)$.

\section{RESULTS}

The blood haemoglobin and plasma ferritin concentrations were measured as indices of $\mathrm{Fe}$ status (Table 3). While the haemoglobin appeared to have decreased slightly during the latter half of the experiment, the decrease was not significant. The plasma ferritin concentration decreased significantly with the duration of the experiment and the amount of blood taken as samples.

The retention of radioFe from the LFD single meal given in the morning on two consecutive days gave on average $78 \%$ higher absorption values compared with those obtained for the retention of radioFe from the same diet served at every meal on both days (Table 4). The values for the absorption of Fe obtained from the two measurements were significantly correlated $(r 0.77 ; P=0.009 ; n 10)$.

During the second study period the same design was used and the same subjects were given an HFD. With the HFD the retention from the single morning meal was $48 \%$ higher than that from the $2 \mathrm{~d}$ diet. This measure was not significant nor was it significantly different from the increase with the LFD. Again the two measures of Fe absorption correlated well with each other $(r 0.89 ; P=0.001 ; n 10)$.

The absorption of ${ }^{55} \mathrm{Fe}$ and ${ }^{59} \mathrm{Fe}$ given together as reference doses on two consecutive days at the end of the study was essentially identical (absorption ratio 1.00 (SE 0.001)).

Fe absorption from either of the diets or from the reference doses was not significantly correlated with the plasma ferritin concentration. No significant correlation was found within individuals for the absorption of Fe from the two diets whether they were measured from the morning meals or all meals on two consecutive days. 
Table 3. Values for iron status variables $3 d$ before the beginning and $1 d$ after the end of each of the low- and high-fibre diet periods*

(Means with their standard errors, except geometric means with their standard errors for ferritin)

\begin{tabular}{|c|c|c|c|c|c|c|c|c|c|c|c|}
\hline & \multicolumn{4}{|c|}{ Low-fibre diet } & \multicolumn{4}{|c|}{ High-fibre diet } & \multirow{2}{*}{\multicolumn{3}{|c|}{$\begin{array}{c}\text { Statistical analysis: } \\
\text { ANOVA }\end{array}$}} \\
\hline & \multicolumn{2}{|c|}{ Before } & \multicolumn{2}{|c|}{ After } & \multicolumn{2}{|c|}{ Before } & \multicolumn{2}{|c|}{ After } & & & \\
\hline & Mean & SE & Mean & $\mathrm{SE}$ & Mean & SE & Mean & SE & $F$ & $\mathrm{df}$ & $P$ \\
\hline $\begin{array}{l}\text { Haemoglobin } \\
(\mathrm{g} / \mathrm{l})\end{array}$ & $146 \cdot 7$ & $2 \cdot 30$ & $149 \cdot 0$ & $3 \cdot 24$ & $143 \cdot 3$ & $2 \cdot 32$ & $142 \cdot 1$ & 3.09 & $2 \cdot 88$ & 3 & 0.055 \\
\hline Ferritin & $60 \cdot 3^{a}$ & 1.29 & $49 \cdot 0^{b}$ & $1 \cdot 30$ & $42 \cdot 6^{\mathrm{b} . \mathrm{c}}$ & $1 \cdot 32$ & $36 \cdot 3^{\mathrm{c}}$ & $1 \cdot 32$ & 17.99 & 3 & $<0.001$ \\
\hline
\end{tabular}

a, b, c Means with unlike letter superscript letters were significantly different $(P \leqslant 0.05)$.

* For details of diets and procedures, see Tables 1 and 2 and pp. 282-286.

Table 4. Individual results of iron absorption (\% retention of radioFe) for the low- and high-fibre diets and the reference dose*

(Means and with their standard errors)

\begin{tabular}{|c|c|c|c|c|c|c|c|c|c|}
\hline \multirow{3}{*}{$\begin{array}{c}\text { Subject } \\
\text { no. }\end{array}$} & \multicolumn{9}{|c|}{ Fe absorption } \\
\hline & \multicolumn{3}{|c|}{ Low-fibre diet } & \multicolumn{3}{|c|}{ High-fibre diet } & \multicolumn{3}{|c|}{ Reference dose ( $3 \mathrm{mg} \mathrm{Fe}$ ) } \\
\hline & ${ }^{55} \mathrm{Fe}$ & ${ }^{59} \mathrm{Fe}$ & ${ }^{85} \mathrm{Fe}:{ }^{59} \mathrm{Fe}$ & ${ }^{55} \mathrm{Fe}$ & ${ }^{59} \mathrm{Fe}$ & ${ }^{55} \mathrm{Fe}:{ }^{59} \mathrm{Fe}$ & ${ }^{55} \mathrm{Fe}$ & ${ }^{59} \mathrm{Fe}$ & ${ }^{55} \mathrm{Fe}:{ }^{59} \mathrm{Fe}$ \\
\hline 1 & 1.05 & 1.04 & 1.01 & $2 \cdot 00$ & 0.78 & 2.58 & $46 \cdot 63$ & 46.07 & 1.01 \\
\hline 2 & 3.85 & $1 \cdot 25$ & 3.07 & $2 \cdot 16$ & $2 \cdot 92$ & 0.74 & $43 \cdot 36$ & $42 \cdot 81$ & 1.01 \\
\hline 3 & $4 \cdot 62$ & 1.93 & $2 \cdot 40$ & 3.95 & $2 \cdot 37$ & 1.67 & 43.71 & $44 \cdot 01$ & 0.99 \\
\hline 4 & $2 \cdot 68$ & $1 \cdot 16$ & $2 \cdot 31$ & $2 \cdot 99$ & 0.99 & 3.02 & $58 \cdot 77$ & 58.07 & 1.01 \\
\hline 5 & 1.85 & 1.05 & 1.76 & 0.66 & 0.90 & 0.73 & $64 \cdot 22$ & $64 \cdot 30$ & 1.00 \\
\hline 6 & $4 \cdot 67$ & $3 \cdot 57$ & $1 \cdot 31$ & $4 \cdot 50$ & $3 \cdot 70$ & 1.22 & 46.89 & $48 \cdot 23$ & 0.97 \\
\hline 7 & $2 \cdot 40$ & 1.69 & $1 \cdot 42$ & $3 \cdot 11$ & $2 \cdot 76$ & $1 \cdot 13$ & $28 \cdot 82$ & $28 \cdot 51$ & 1.01 \\
\hline 8 & 0.98 & 0.78 & $1 \cdot 26$ & $2 \cdot 31$ & $2 \cdot 24$ & 1.03 & $37 \cdot 37$ & $37 \cdot 04$ & $1 \cdot 01$ \\
\hline 9 & $4 \cdot 25$ & $2 \cdot 47$ & 1.72 & $3 \cdot 11$ & 2.89 & 1.08 & 89.02 & $89 \cdot 71$ & 0.99 \\
\hline 10 & $2 \cdot 35$ & 1.52 & 1.54 & $9 \cdot 73$ & $6 \cdot 23$ & 1.56 & 82.57 & 81.86 & $1 \cdot 01$ \\
\hline Mean & $2 \cdot 87^{\mathrm{a}}$ & $1.65^{\mathrm{b}}$ & 1.78 & $3 \cdot 45$ & $2 \cdot 58$ & 1.47 & $54 \cdot 13$ & 54.06 & 1.00 \\
\hline $\mathrm{SE}$ & 0.44 & 0.27 & 0.2 & 0.48 & 0.51 & 0.24 & $6 \cdot 15$ & $6 \cdot 18$ & 0.004 \\
\hline
\end{tabular}

a,b Means with unlike superscript letters in the low-fibre-diet period were significantly different $(P<0.01)$.

* For details of diets and procedures, see Tables 1 and 2 and pp. 282-286.

\section{DISCUSSION}

Measurement of the absorption and retention of radioisotopes of Fe from single meals has been for some time the method of choice for the assessment of the effects of factors which enhance or inhibit Fe absorption. In the present study the single-meal design was compared with a modified design in which all three meals of the same diet as that consumed as a single meal were labelled with a radioisotope of Fe during two consecutive days. The absorption values obtained for the LFD with the single-meal technique (apparent absorption 2.87\%) were on average almost $80 \%$ higher than those obtained for the same diet with the modified technique (apparent absorption $1.65 \%$ ). The Fe absorption from the HFD measured with the single meal technique was less than $50 \%$ higher than that measured with the modified 
technique and the difference was not significant. As the absorption of the reference doses of ${ }^{55} \mathrm{Fe}$ and ${ }^{59} \mathrm{Fe}$ was almost identical, there is no reason to believe that a method error was responsible for these systematic differences in Fe absorption from single meals and wholeday diets. The differences between the ratio of the two absorption measurements from the LFD and the HFD (1.78 v. 1.48) was not significantly different. As the present study was made within the framework of a larger study which was not designed primarily to compare the LFD and HFD, no crossover was used. The Fe status of the subjects, as reflected in the plasma ferritin concentration, decreased between the LFD and HFD periods mainly due to blood sampling. This as well as other unnoticed changes may have occurred between the test periods but it is unlikely that the change in Fe status is the main cause of the comparatively low absorption ratio during the HFD period.

There may be several explanations which either separately or combined may explain the differences observed between the results of the single-meal design and the all-day design. One of them may be that the single meal was given after a $12 \mathrm{~h}$ period of fasting (overnight), compared with $4 \mathrm{~h}$ without food before the lunch and dinner meals. This difference in the length of the fasting period may have caused greater absorption from the breakfast meal than the average for the same diet throughout the whole day. This would appear to contradict the results of Bjorn-Rasmussen et al. (1974) who found a higher absorption of Fe from lunch and dinner compared with that of a breakfast meal. The meals in that study, however, were not identical. The lunch and dinner contained fish and meat, which are known to stimulate Fe absorption, and the breakfast contained more phytic acid, which is known to inhibit Fe absorption.

A second factor which may explain the differences in results is that the single meal given in the morning represented only one-seventh of the total daily intake and, therefore, only one-seventh of the total $\mathrm{Fe}$ intake. In the present study the ratios of $\mathrm{Fe}, \mathrm{Ca}$, phytic acid and fibre to one another were equal in all meals in order to avoid the possibility that differences in absorption between the single meal and all-day design could be caused by differences in relative proportions of enhancers and inhibitors among meals, as in the studies of Gleerup et al. (1995) and Cook et al. (1991). As the intake of Fe in the morning was comparatively low, this may have given rise to a higher Fe absorption from the morning meal.

On the basis of the results of the present study, we recommend that radioFe-labelled test diets should be given at all meals during the test day(s) and not as single meals in the morning after an overnight fast as the values obtained with the single-meal technique may be inflated. In some situations the single-meal technique may exaggerate the effects of dietary factors on Fe absorption as suggested by Cook et al. (1991). Therefore, we recommend that the results of single-meal studies as a measure of Fe absorption should be interpreted with caution.

The authors wish to thank Professor Wolfgang Frech for valuable discussions concerning analytical methods. They also wish to thank Ms Margareta Holmgren, Ms Ann-Mari Åhrén, Ms Åsa Ågren and Ms Jeannette Molin for skilful technical assistance. This study was supported by the Swedish Council for Forestry and Agricultural Research (SJFR) and the Swedish Dairy Association (SMR).

\section{REFERENCES}

Asp, N.-G., Johansson, C.-G., Hallmer, H. \& Siljestrom, M. (1983). Rapid enzymatic assay of insoluble and soluble dietary fiber. Journal of Agricultural and Food Chemistry 31, 476-482.

Björn-Rasmussen, E., Hallberg, L., Isaksson, B. \& Arvidsson, B. (1974). Food iron absorption in man. Applications of the two-pool extrinsic tag method to measure heme and nonheme iron absorption from the whole diet. Journal of Clinical Investigation 53, 247-255. 
Bothwell, T. H., Charlton, R. W., Cook, J. D. \& Finch, C. A. (editors) (1979). Radioiron measurements. In Iron Metabolism in Man, pp. 405-410. Oxford: Blackwell Scientific Publications.

Cook, J. D., Dassenko, S. A. \& Lynch, S. R. (1991). Assessment of the role of nonheme-iron availability in iron balance. American Journal of Clinical Nutrition 54, 717-722.

Eakins, J. D. \& Brown, D. A. (1966). An improved method for the simultaneous determination of iron-55 and iron-59 in blood by liquid scintillation counting. International Journal of Applied Radiation and Isotopes 17, 391-397.

Expert Scientific Working Group (1985). Summary of a report on assessment of the iron nutritional status of the United States population. American Journal of Clinical Nutrition 42, 1318-1330.

Food and Agriculture Organization/World Health Organization/United Nations University (1985). Report of a Joint FAO/WHO/UNU Expert Consultation. World Health Organization Technical Report series no. 724, pp. 1-206. Geneva: WHO.

Frank, A. (1976). Automated wet ashing and multi-metal determination in biological materials by atomicabsorption spectrometry. Zeitung Analytical Chemistry 279, 101-102.

Gleerup, A., Rossander-Hultén, L. \& Hallberg, L. (1995). Iron absorption from the whole diet in relation to calcium intake. A comparison of the effect of two different distributions of the daily intake of calcium. American Journal of Clinical Nutrition 61, 97-104.

Hallberg, L. \& Björn-Rasmussen, E. (1972). Determination of iron from whole diet. A new two-pool model using two radioiron isotopes given as haem and non-haem iron. Scandinavian Journal of Haematology 9, $193-197$.

Hallberg, L., Brune, M., Erlandsson, M., Sandberg, A. S. \& Rossander-Hulten, L. (1991). Calcium: effect of different amounts on nonheme- and heme-iron absorption in humans. American Journal of Clinical Nutrition $53,112-119$.

International Committee for Standardization in Human Blood (1965). Recommendations and requirements for haemoglobinometry in human blood. Journal of Clinical Pathology 18, 353-355.

Snedecor, G. W. \& Cochran, W. G. (1980). In Statistical Methods, 7th ed., pp. 258-298. Ames, IA, USA: The Iowa State University Press.

Swedish National Food Administration (1988). Food Composition Tables, 2nd ed. Uppsala, Sweden: Swedish National Food Administration. 